E3S Web of Conferences 1, 38002 (2013)

DOI: $10.1051 / \mathrm{e} 3 \operatorname{sconf} / 20130138002$

(c) Owned by the authors, published by EDP Sciences, 2013

\title{
Societal benefits from EU reduction measures to decrease lead levels in the environment; Combining results from the EU funded projects INTARESE and HEIMTSA
}

\author{
J. G. E. A. Bierkens ${ }^{1}$ \\ ${ }^{1}$ Exposure and Risk Assessment Modeling, Flemish Institute for Technological Research - Vito, Vlasmeer 7, B-2400 \\ Mol, BELGIUM,johan.bierkens@vito.be
}

\begin{abstract}
The current paper combines the results of two Sixth Framework Program EU research projects aimed at developing and testing methods for integrated assessment of health risks from environmental stressors, i.e. the INTARESE and the HEIMTSA project, both of which covered a case study on environmental lead. The INTARESE case study on lead in Europe was meant to illustrate the use of the Integrated Monitoring Framework Strategy to assess the health outcome of environmental pollution by evaluating the associations between lead in various environmental compartments (air, soil, dust, drinking water and diet) and lead concentrations in blood $(\mathrm{B}-\mathrm{Pb})$ for various age-related sub-populations. The case study was aimed to investigate whether environmental, exposure and biomonitoring data at general population level, covering all EU member states, could be integrated. The HEIMTSA case study on the other hand involved the full chain assessment from policy drivers to health effect quantification of lead exposure through locally produced food on loss of IQ in pre-school children at the population level across the EU-27, including monetary valuation of the estimated health impact. Main policy scenarios cover the period from 2000 to 2020 and include the most important Community policy developments expected to affect the environmental release of lead $(\mathrm{Pb})$ and corresponding human exposure patterns. Three distinct scenarios were explored: the emission situation based on 2000 data, a business-as-usual scenario (BAU) up to 2010 and 2020 and a scenario incorporating the most likely technological change expected (Most Feasible Technical Reductions, MFTR) in response to current and future legislation. Analysing environmental data, significant correlations were found between $\mathrm{B}-\mathrm{Pb}$ and the concentrations of $\mathrm{Pb}$ in air and diet. The significant decrease of the $\mathrm{Pb}$ in air over time from $0.31 \mu \mathrm{g} / \mathrm{m}^{3}(\mathrm{P} 95$; 0.94; $\mathrm{n}=98)$ prior to 1990 to $0.045 \mu \mathrm{g} / \mathrm{m}^{3}(\mathrm{P} 95: 0.11 ; \mathrm{n}=256)$ in 2007 (latest observations included) $(\Delta=-85 \%)$ corresponds to a decline in $\mathrm{B}-\mathrm{Pb}$ by $48 \%$ and $57 \%$ in adult women and adult men, respectively. The corresponding decline in $\mathrm{B}-\mathrm{Pb}$ in primary school children is $32 \%$. The observed $\mathrm{B}-\mathrm{Pb}$ levels (biomonitoring data) for each age category from the INTARESE project were translated into an average loss of IQ points/individual using the methodology developed in the HEIMTSA project based on a literature survey, i.e. using an empirical relationship based on a meta-analysis performed by Schwartz (1994). The calculated losses in IQ points were subsequently further translated into the average cost/child using a cost estimate of $€ 10.000$ per loss of IQ point based on data from a literature review. In applying the methodology for estimating the health impact and monetary valuation of IQ loss developed during the HEIMTSA project to the INTARESE biomonitoring data, we estimate the societal benefit from the reduction strategies implemented to decrease environmental lead levels in Europe for primary-school children, representing a vulnerable population, to amount to $2.5 \times 10^{11}$ Euro at EU27 level.
\end{abstract}

Key words: Heavy metals, impact assessment, IQ loss, lead, monetary valuation, primary-school children

\section{Introduction}

The case studies reported here are part of the efforts under two distinct EU Sixth Framework Program research projects, i.e. INTARESE (Integrated Assessment of Health Risks of Environmental Stressors in Europe) and HEIMTSA (Health and Environment Integrated Methodology and Toolbox for Scenario Assessment), aimed at developing and testing methods for integrated assessment of health risks from environmental stressors. 
The results of each case study separately have been published previously (Bierkens et al., 2011; Bierkens et al., 2012). For the current paper we combine both results, i.e. apply the methodology for estimating the health impact and monetary valuation of IQ loss developed during the HEIMTSA project to the INTARESE biomonitoring data, in order to estimate the societal benefits gained from the different reduction strategies implemented to decrease environmental lead levels in Europe, the ban of leaded petrol being the most drastic.

Lead $(\mathrm{Pb})$ was selected for the case studies as it is found in several micro-environments across Europe (and the world) and is subject to long-range environmental transport processes. Moreover, it is of both anthropogenic and natural origin and human exposure is affected by various Community policies addressing different economic sectors such as transport, industry, agriculture, as well as environmental and public health protection legislation such as the drinking water directive.

Lead is also probably the most intensively biomonitored chemical with continued concern about its potential health impact (Smolders and Schoeters, 2007). $\mathrm{Pb}$ is an ubiquitous environmental pollutant with a long history in human biomonitoring (HBM) programs. Probably, it was and continuous to be one of the first pollutants to receive widespread attention as a causative agent for health-related effects (Apostoli et al., 2002; Landrigan et al., 2006; Jones et al., 2009). Human biomonitoring has historically focused on determining $\mathrm{Pb}$ concentrations in blood (B-Pb) as $\mathrm{B}-\mathrm{Pb}$ has played an important role in the elucidation of the link between $\mathrm{Pb}$ in the environment and health effects such as loss of IQ or neurological disorders (Goyer, 1996; Lanphear et al., 2006; Jones et al., 2009).

\section{Materials and Methods}

Data have been collected on $\mathrm{Pb}$ in blood, in air, soil, house dust, drinking-water and on $\mathrm{Pb}$ dietary exposure with the aim to construct chronological records at country level for Europe as part of the INTARESE project. In general, only environmental data that might affect the general population at large were incorporated in the data base with the exception of data on contaminated areas from publications that report coupled data, i.e. data both on $\mathrm{B}-\mathrm{Pb}$ and one or more $\mathrm{Pb}$ concentrations in the environment. For this, publicly available national and international data bases and papers or reports in the open or gray literature were accessed and depending on the statistics reported, entries on mean, geometric mean, P5, P50, P90, P95, P97.5, minimum and maximum were included for each variable. All data were stored in an Access database. Details on consulted sources per data type are given in Bierkens et al. (2011).

Apart from information on the country/region and year of sampling which is included for all variables, additional information on age, gender and the type of study were added to the biomonitoring data whenever available. Information on the type of diet study (duplicate meal, market basket and total diet studies) and on the type of land use (rural, urban, industrial) was registered for the dietary exposure data and environmental monitoring data, respectively. Subsequently, the environmental monitoring and dietary exposure data were matched with the database- $\mathrm{Pb}$ data with regard to country/region and the year of sampling.

In order to predict costs resulting from internal exposure to $\mathrm{Pb}$ as a result of consuming local produce, the $\mathrm{B}-\mathrm{Pb}$ levels estimates were translated into an average loss of IQ points/individual. For this purpose a literature survey was performed as part of the HEIMTSA project. The effect on children's IQ was estimated with a function derived in a meta-analysis study by Schwartz (1994) who found that the average effect observed in 8 studies that met quality assurance criteria is a 2.6 IQ point decrease for a B-Pb increase from 10 to $20 \mu \mathrm{g} / \mathrm{dL}$, a function which is also used by the US EPA in support of their policies. A cost estimate of $€ 10,000$ per IQ point derived by Sparado and Rabl (2004) has been used for the current paper to translate the loss in IQ points into average costs/child. More details can be found in Bierkens et al. (2012).

\section{Results and Discussion}

Details on $\mathrm{Pb}$ levels in different environmental compartments and $\mathrm{B}-\mathrm{Pb}$ can be found in Bierkens et al. (2011). The B-Pb data for adults collected in the context of this survey encompass a period of nearly 30 years, ranging from 1981 until 2008. For primary- and preschool children the earliest observations date from 1983 to 1999 , respectively. Over this period a significant $(\mathrm{P}<0.05)$ decline in $\mathrm{B}-\mathrm{Pb}$ levels is observed both in adults and in primary school children (Fig. 1). As most data were not normally distributed the statistical analyses were performed on $\log 10$-transformed data sets.

Fig. 1. Median $\mathrm{B}-\mathrm{Pb}(\mu \mathrm{g} / \mathrm{dl})$ for different age groups as a

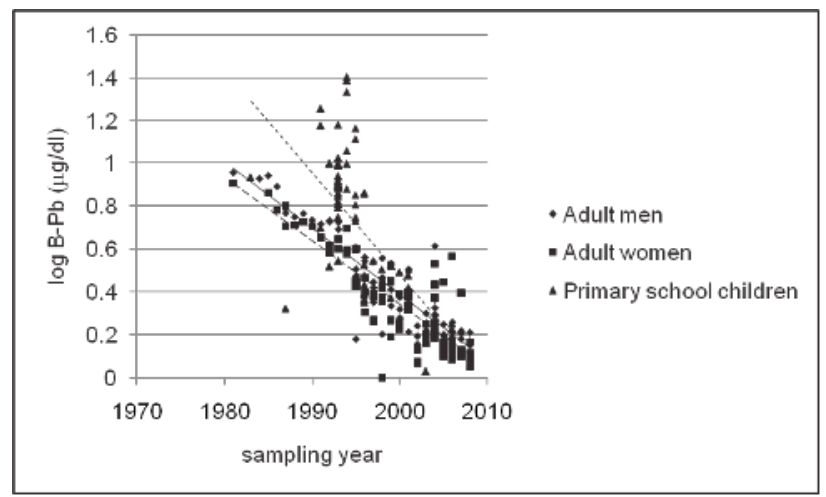

function of time (Bierkens et al, 2011).

Whereas the average $\mathrm{B}-\mathrm{Pb}$ levels in adult women prior to 1990 amount to $6.17 \mu \mathrm{g} / \mathrm{dl}$, the mean $\mathrm{B}-\mathrm{Pb}$ level determined for the years 2005-2008 have declined to $1.97 \mu \mathrm{g} / \mathrm{dl}$. The corresponding levels in adult men for the 
same windows in time are slightly higher, i.e. $7.33 \mu \mathrm{g} / \mathrm{dl}$ and $2.28 \mu \mathrm{g} / \mathrm{dl}$, respectively.

Data for primary school children in the early 1990's are biased by a large number of data for children from Poland (89 out of 123 entries) with a mean value of 7.78 $\mu \mathrm{g} / \mathrm{dl}$. When the Polish data are excluded the significant decline over time remains but in this case the average B$\mathrm{Pb}$ levels in the period before 1990 and after 2005 in primary school children decrease from $5.35 \mu \mathrm{g} / \mathrm{dl}$ to 1.71 $\mu \mathrm{g} / \mathrm{dl}$. The corresponding regression equation for primary school children excluding Polish data is $\log \mathrm{B}-\mathrm{Pb}=52.32$ -0.026 year $\left(r^{2}=0.5886 ; p \leq 0.00001\right)$. Although a decline in $\mathrm{B}-\mathrm{Pb}$ levels in pre-school children is observed, it is not statistically significant $(\mathrm{P}<0.05)$. Expressed as a percentage of the earliest observation the decline in $\mathrm{B}-\mathrm{Pb}$ levels at the end of the observation period for adult women, men and primary school children amounts to 48 , 57 and $32 \%$, respectively.

When the above mentioned observed decline of B$\mathrm{Pb}$ levels over time for each age category are translated into an average decrease in loss of IQ points/individual using the empirical relationship by Schwartz (1994) and a cost reduction estimate of $€ 10.000$ per loss of IQ point, an average cost reduction per individual of $€ 10920$, $€ 13130$ and $€ 9464$ are calculated for adult woman, adult men and primary school children, respectively. When the vulnerable group of primary school children is taken as an example this would mean that for the European Union (EU27) at large, with a total of $25,847,651$ primary school children (Eurostat), the reduction measures taken to reduce lead levels in the environment have reduced the societal cost due to loss of IQ via lead exposure with an estimated $2.5 \times 10^{11}$ Euro.

\section{Conclusions}

For the current paper we have combined the results of two EU funded research projects, i.e. apply the methodology for estimating the health impact and monetary valuation of IQ loss developed during the HEIMTSA project for modelling different exposure scenario's, to the real world INTARESE biomonitoring data, in order to estimate the societal benefit gained from the different reduction strategies implemented by the Commission to decrease environmental lead levels in Europe, the ban of leaded petrol being the most drastic. In doing so we took advantage of two projects in modeling and impact assessment and brought together rich datasets for a new modeling exercise in order to contribute to a framework for studying exposure, risk and impact assessment across diverse settings.

Further harmonized and accessible data collection in environmental and other exposure media (food, drinking water) and further refinements to the empirical relationship between $\mathrm{B}-\mathrm{Pb}$ and loss of IQ and to the costs associated with decreased IQ may be envisaged. This case study is therefore only an example of how the full chain was addressed.

\section{Acknowledgements}

This research has been performed within the context of the EU funded Integrated Research Projects INTARESE (Integrated Assessment of Health Risks of Environmental Stressors in Europe, see www. intarese.org) and HEIMTSA (Health and Environment Integrated Methodology and Toolbox for Scenario Assessment, see www.heimtsa.eu/Home/tabid/152/Default.aspx).

\section{References}

Apostoli P, Baj A, Bavazzano P, Ganzi A, Neri G, Ronchi A, et al. Blood lead reference values: the results of an Italian polycentric study. Sci Total Environ 2002;287:1-11.

Bierkens J, Smolders R, Van Holderbeke M, Cornelis C. Predicting blood lead levels from current and past environmental data in Europe. Sci Total Environment 2011; 409: 5101-5110.

Bierkens J, Buekers J, Van Holderbeke M, Torfs R. Health impact assessment and monetary valuation of IQ loss in pre-school children due to lead exposure through locally produced food. Sci Total Environment 2012; 414:90-97.

Goyer RA. Results of lead research: prenatal exposure and neurological consequences. Environ Health Perspect 1996;104:1050-4.

Jones RL, Horna DM, Meyer PA, Brody DJ, Caldwell KL, Pirkle JL, et al. Trends in blood lead levels and blood lead testing among US children aged 1 to 5 years, 1988-2004. Pediatrics 2009;123:376-85.

Landrigan P, Nordberg M, Lucchini R, Nordberg G, Grandjean P, Iregren A, et al. The declaration of Brescia on prevention of the neurotoxicity of metals. Am J Ind Med 2006;50:709-11.

Lanphear BP, Hornung R, Ho M, Howard CR, Eberly S, Knauf K. Environmental lead exposure during early childhood. J Pediatr 2002;140:40-7.

Smolders R, Schoeters G. Identifying opportunities and gaps for establishing an integrated EDR-triad at a European level. Int $\mathrm{J}$ Hyg Environ Health 2007;210:253-7.

Schwartz J. Low-level lead exposure and children's IQ: a meta-analysis and search for a threshold. Environ Res 1994;65:42-55.

Spadaro JV, Rabl A. Pathway analysis for populationtotal health impacts of toxic metal emissions. Risk Anal 2004; 24:1121-41. 